\title{
A systematic review exploring the bidirectional relationship between puberty and autoimmune rheumatic diseases
}

Nina M. de Gruijter ${ }^{1,2}$, Meena Naja ${ }^{1}$, Hannah Peckham ${ }^{1}$, Anna Radziszewska ${ }^{1}$, Matthew Kinsella ${ }^{3}$, James Glenister ${ }^{3}$, Elizabeth C. Rosser ${ }^{1,2}$, Gary E. Butler ${ }^{4}$, Elizabeth C. Jury ${ }^{2}$ and Coziana Ciurtin ${ }^{1 *}$ (D)

\begin{abstract}
Background: Autoimmune rheumatic diseases (ARDs) are associated with a significant sex-bias, which becomes more evident post-puberty. This systematic review aims to elucidate the bidirectional relationship between puberty and ARD-related outcomes.

Methods: Studies published in English until October 2019 were identified using a systematic search of endocrinology and rheumatology literature. Information was extracted on study design, sample size, demographics, puberty outcome measures, disease outcome measures, and main findings. The methodological quality of the studies included was analysed using the Newcastle-Ottawa Scale (NOS).

Results: Sixteen non-randomised studies reporting on the impact of puberty on ARD outcomes $(n=7)$, ARD impact on puberty-related outcomes $(n=8)$, or both $(n=1)$ have been identified. The impact of puberty on ARD outcomes were investigated in patients with juvenile idiopathic arthritis (JIA)-associated uveitis $(n=1)$, juvenile systemic lupus erythematosus (JSLE) $(n=5)$ or in healthy controls who developed adult-onset SLE $(n=1)$ or had non-specific symptoms $(n=1)$. The impact of ARD on puberty outcomes was explored in JIA $(n=4)$ and JSLE $(n=$ 3). Quality assessment of studies showed a small to moderate risk of bias overall (NOS 4-9/9). Due to large heterogeneity of the studies it was not possible to perform a meta-analysis. Multiple studies reported on delayed puberty in patients with JIA/JSLE, menstrual and hormonal abnormalities, and lower height and weight than controls. Earlier (pre-pubertal) onset of JSLE was correlated with more severe disease and more need for systemic treatment.

Conclusion: A bidirectional relationship exists between puberty and ARDs; however, more and better research is required to elucidate the complexity of this relationship. We propose puberty-related clinical assessments in patients with ARDs, which can improve patient outcomes and facilitate future research.
\end{abstract}

Keywords: Autoimmune rheumatic diseases, Puberty, Adolescence, Sex hormones, Systemic lupus erythematosus, Juvenile idiopathic arthritis

\footnotetext{
* Correspondence: c.ciurtin@ucl.ac.uk

${ }^{1}$ Centre for Adolescent Rheumatology Versus Arthritis, Department of Medicine, University College London, Rayne Building, London W1CE 6JF, UK Full list of author information is available at the end of the article
}

(c) The Author(s). 2021 Open Access This article is licensed under a Creative Commons Attribution 4.0 International License, which permits use, sharing, adaptation, distribution and reproduction in any medium or format, as long as you give appropriate credit to the original author(s) and the source, provide a link to the Creative Commons licence, and indicate if changes were made. The images or other third party material in this article are included in the article's Creative Commons licence, unless indicated otherwise in a credit line to the material. If material is not included in the article's Creative Commons licence and your intended use is not permitted by statutory regulation or exceeds the permitted use, you will need to obtain permission directly from the copyright holder. To view a copy of this licence, visit http://creativecommons.org/licenses/by/4.0/ The Creative Commons Public Domain Dedication waiver (http://creativecommons.org/publicdomain/zero/1.0/) applies to the data made available in this article, unless otherwise stated in a credit line to the data. 


\section{Background}

Adolescence and puberty are associated with significant physical, physiological, psychological and immunological changes. The timing of puberty is important, as both early and late puberty correlate with adverse health outcomes later in life, such as diabetes and cardiovascular disease [1]. Puberty is initiated and mediated by sex hormones, which also influence the development and regulation of the immune system [2]. Epidemiological studies have shown that pubescent and post-pubescent males and females are at risk of developing autoimmune rheumatic diseases (ARDs) in a sex-biased manner, and that the age at disease onset often differs between sexes $[3,4]$.

The sex bias in the incidence of autoimmune diseases has long been recognised, with females being at significantly higher risk of developing conditions such as systemic lupus erythematosus (SLE), scleroderma, Sjögren's syndrome, rheumatoid arthritis (RA), autoimmune thyroid disease, multiple sclerosis (MS), and polyautoimmunity $[2,5]$. Furthermore, in many ARDs, the average age of disease onset is significantly earlier in females than in males. The female population undergoes at least two major endocrinological changes in their lifetimes: puberty and the menopause, between which there are constant cyclical hormonal changes, and possibly pregnancy and breastfeeding. Males experience major physiological and psychological changes during puberty as well, but show a gradual decline in hormonal levels after age 40, rather than the abrupt change seen in females during menopause [6]. The endocrinological changes at each of these milestones affect both the innate and adaptive immune systems. T-cell autoimmunity in particular is upregulated post-puberty in animal models [5]; however, there is a limited understanding of the physiological (molecular and cellular) mechanisms for sex-specific immune modulation.

Previous research has observed a relationship between puberty and the onset of various autoimmune conditions. The incidence of SLE, autoimmune thyroid disease, and MS increases in peri- and post-pubescent females, suggesting that sex hormone changes at puberty play an immunomodulatory role in triggering ARD onset and development [5]. The prevalence of juvenile SLE (JSLE) in females has been observed to rise from 6.7 per 100,000 at age seven to 34.6 per 100,000 at age fifteen (versus almost zero per 100,000 at age seven and 7.8 per 100,000 at age fifteen in males) [7]. The female: male incidence ratio in SLE is most pronounced after puberty and before the menopause (from 2:1 to 6:1 pre-puberty, $7: 1$ to $15: 1$ post-puberty, and $3: 1$ to $8: 1$ post-menopause) $[8,9]$ suggesting that the increased sex hormone levels present from puberty to the menopause increase susceptibility to an autoimmune state. Similarly, MS is rarely seen pre-puberty, and the female: male ratio of MS onset in pre-pubertal children is near equal. Postpuberty, MS incidence increases in both sexes with a 2.2: 1 female: male ratios [10]. Furthermore, there is emerging evidence linking the age at menarche with the risk of autoimmunity in females. Studies have found that an earlier age at menarche increases the risk of RA [11]; later age at menarche decreases the risk of MS [12]; JSLE is associated with a trend for later onset menarche [13]; and the incidence of psoriasis in females increases during the peri-menarchal period [14].

In addition to triggering autoimmunity, sex hormones can influence the outcome of autoimmune diseases. Testosterone is thought to exert a protective effect against the development of autoimmunity. This has been replicated in animal models, which showed protective effects of testosterone in models of both SLE [15] and arthritis [16, 17]. Oestriol, a sex hormone that is only detectable during pregnancy, is thought to have a protective effect in MS, and may account for the reduced relapse rates observed during pregnancy [4]. Previous research has been directed at understanding the impact of hormonal treatment in autoimmune disease: benefits associated with testosterone treatment have been seen in SLE [18] and arthritis [19]; ongoing clinical trials are finding reduced relapse rates with oestriol treatment in MS [20].

Apart from influencing autoimmune disease onset and outcomes, sex hormones impact the physiological development of bones and muscles during puberty [21]. This is frequently accompanied by non-specific musculoskeletal symptoms [22], and changes in bone and muscle biomarker levels [23, 24], further complicating the assessment of ARD-related symptoms in adolescents.

No previous systematic reviews have addressed the impact of puberty on disease outcome measures in autoimmune rheumatic diseases, or the impact of ARDs on puberty-related outcomes. Few studies are available that have looked at the epidemiology of ARDs during adolescence or focused on the gender bias in autoimmunity in adolescent populations. Understanding the interplay between the neuroendocrine and immune systems will provide insights into the pathogenesis of the peripubertal onset of ARDs, and may change the clinical approach to treatment of these patients in the long term.

\section{Aims}

With this systematic review we aim to elucidate how rheumatological conditions impact puberty, and how physiological changes of puberty influence incidence and manifestations of autoimmune rheumatic diseases.

The objectives of this systematic review are to: 
1. Identify and describe the evidence exploring the bidirectional relationship between puberty and ARDs in adolescence and adulthood;

2. Determine the strength of such evidence.

We hope that the findings of this review will help to inform policy, practice, and future research priorities in the field of puberty and autoimmunity.

\section{Methodology}

\section{Variables of interest}

Our primary outcomes are puberty-related measures in patients with ARDs, such as age at menarche, puberty stages and sex hormone levels. In boys, Tanner stages 4 and 5 are equivalent to the menarche stage in girls. Our secondary variables of interest are ARD-specific outcome measures in peri-pubertal patients, for example disease specific activity and damage scores. We also assessed the strength of evidence found relating to the bidirectional relationship between puberty and ARDs in adolescence and adulthood.

\section{Search strategy}

We used a comprehensive search strategy that aims to be both sensitive and specific. We employed detailed search strategies as deemed appropriate for each database to search Medline, EMBASE and Scopus until October 2019.

An initial search strategy was devised using the MEDL INE thesaurus and indexing system to identify appropriate $\mathrm{MeSH}$ headings and key/text words associated with the terms 'puberty' AND 'autoimmune rheumatic diseases'; "puberty" OR "growth spurt" OR "growth retardation" OR "growth delay" AND "juvenile idiopathic arthritis" OR "systemic lupus erythematosus" OR "SLE" OR "dermatomyositis" OR "enthesitis related arthritis" OR "scleroderma" OR "uveitis"; OR "adolescence" AND "juvenile idiopathic arthritis" OR "systemic lupus erythematosus" OR "SLE" OR "dermatomyositis" OR "enthesitis related arthritis" OR "scleroderma" OR "uveitis". This search strategy has been adapted for use across all included databases as necessary.

The references of papers and review articles were manually checked to ensure inclusion of studies not retrieved through the computerised search method.

\section{Inclusion criteria}

The following studies were included:

1. Studies that include autoimmune rheumatic disease patients of pubertal age, including studies that compare pre- and post-pubertal populations.

2. Prospective and retrospective studies of ARD patients that assess the impact of puberty factors on their disease, or the impact of their disease and/or treatment on puberty outcomes.

The study types included are: observational studies (cohort studies, case-control studies, and cross-sectional studies); experimental studies (randomized controlled trials, controlled clinical trials); case-reports, case-series and abstracts at conferences including subjects with ARDs; studies reporting on incidence/prevalence, clinical and serological ARD features, puberty markers (including clinical assessment, hormone levels or body height/ growing patterns), treatment, quality of life, etc.

\section{Exclusion criteria}

The following studies were excluded: studies in other languages than English, review articles, animal models studies, commentaries, editorials, questionnaire studies, duplicates, and papers not relevant to the topic.

\section{Stages in the literature search}

The protocol was finalised in December 2019. The various stages of this literature search were summarised using the Preferred Reporting of Systematic Reviews and Meta-Analysis (PRISMA) flow chart format to visualise the processes and findings of the review.

\section{Classification of result resources}

Data extraction sheets and tables were developed, tailored to the resources found.

\section{Study selection}

Titles and abstracts were screened and independently assessed for eligibility by two reviewers (MK and JG) and the conflicts were resolved by CC. Full-text papers were evaluated in duplicate by AR and HP. Any disagreement regarding their eligibility was resolved by discussion with a third reviewer (CC). The agreement between the reviewers was assessed by Kappa statistic.

\section{Data extraction and synthesis}

Data extraction was independently performed by two reviewers (AR and $\mathrm{HP}$ ) and discrepancies were resolved through discussion with a third reviewer (CC). We extracted the following information from all the eligible studies: 1) year of publication; 2) country of publication; 3) study design; 4) sample size; 5) demographics of patient group and controls; 6) puberty outcome measures; 7) main findings. In cases where data were not available in the manuscripts, we contacted the authors of relevant papers for additional information.

\section{Quality assessment}

The methodological quality of the studies included was analysed using the validated Newcastle-Ottawa Scale (NOS) for non-randomised studies [25], which assesses 
the quality of three broad study aspects: the selection of the study groups, their comparability, and the ascertainment of either the exposure or outcome of interest, for case-control or cohort studies respectively. Each of these three items was assessed and graded (1 or 2 points). In this analysis, studies with NOS scores of 1-3, 4-6, and 7-9, were defined as of low, intermediate, and high quality, respectively.

\section{Results}

We identified a total of 2027 studies using the search strategy detailed above. After checking for duplicates $(n=0), 1992$ papers were excluded as they did not fulfil the selection criteria. The remaining 51 full-length articles were screened in detail and a final number of 16 papers were deemed appropriate to be included in the qualitative analysis (Fig. 1). One out of 16 eligible papers reported both on the puberty impact on autoimmune rheumatic disease outcomes and ARD impact on puberty-related outcome measures. The papers were grouped in two tables to enable the separate exploration of the bidirectional relationship between puberty and ARDs.
After scrutinising the types of outcome measures reported in the eligible papers, we concluded that a quantitative analysis (meta-analysis) was impossible because of the high heterogeneity of the reported outcomes and subjects included in the various studies.

The papers reporting the impact of ARDs on pubertyrelated outcomes $(n=9)$ mainly focused on patients with JIA or juvenile rheumatoid arthritis (JRA) $(n=5)$ and (J) SLE patients $(n=4)$ (Table 1$)$. Of the 8 papers which reported puberty impact on ARD outcomes, 6 papers investigated (J) SLE patients and one paper investigated patients with juvenile idiopathic arthritis (JIA)-associated uveitis (Table 2). We found no eligible studies in patients with dermatomyositis, enthesitis-related arthritis scleroderma, chronic recurrent multifocal osteomyelitis (CRMO) or childhood granulomatosis with polyangiitis. One paper investigated the impact of puberty on the prevalence of ANA positivity and musculoskeletal symptoms, although there was no evidence that patients with these characteristics proceeded to develop an ARD [35]. The papers were published between 1998 and 2019, and most studies were single-centre cohort studies, with limited data on cohort ethnicity; details about ethnicity were only provided in 10 out of 16 papers.

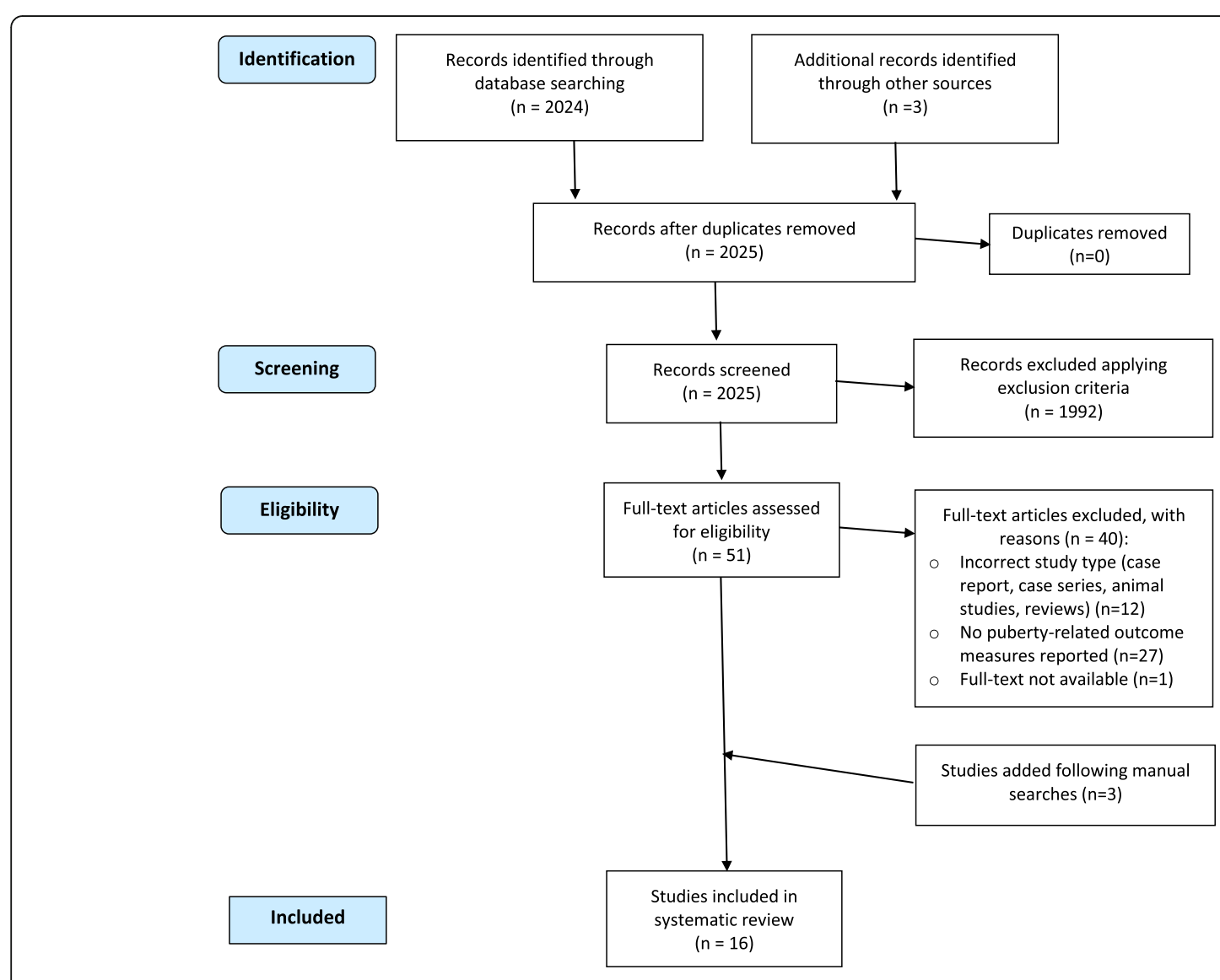

Fig. 1 Flowchart of study selection papers 


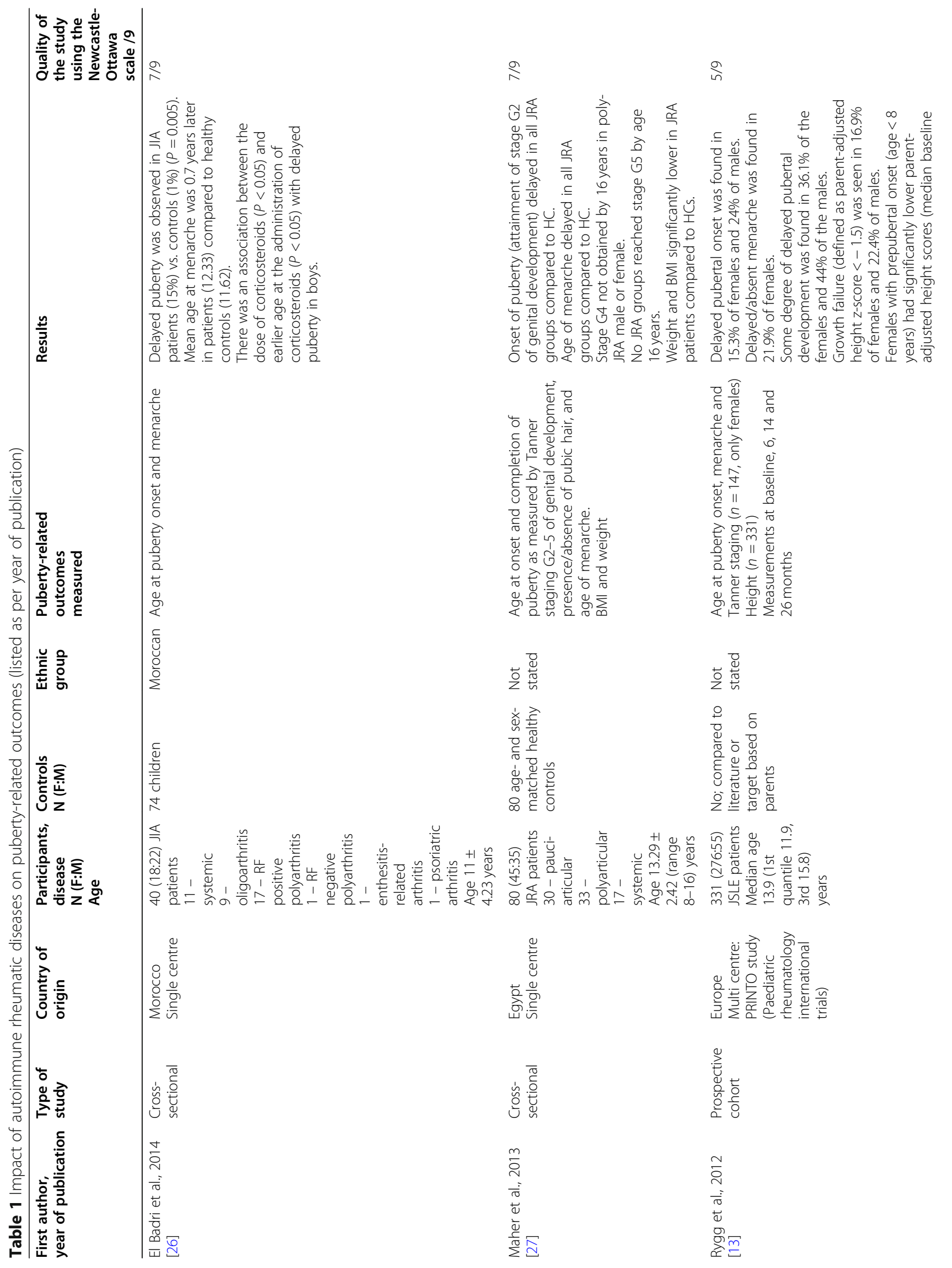




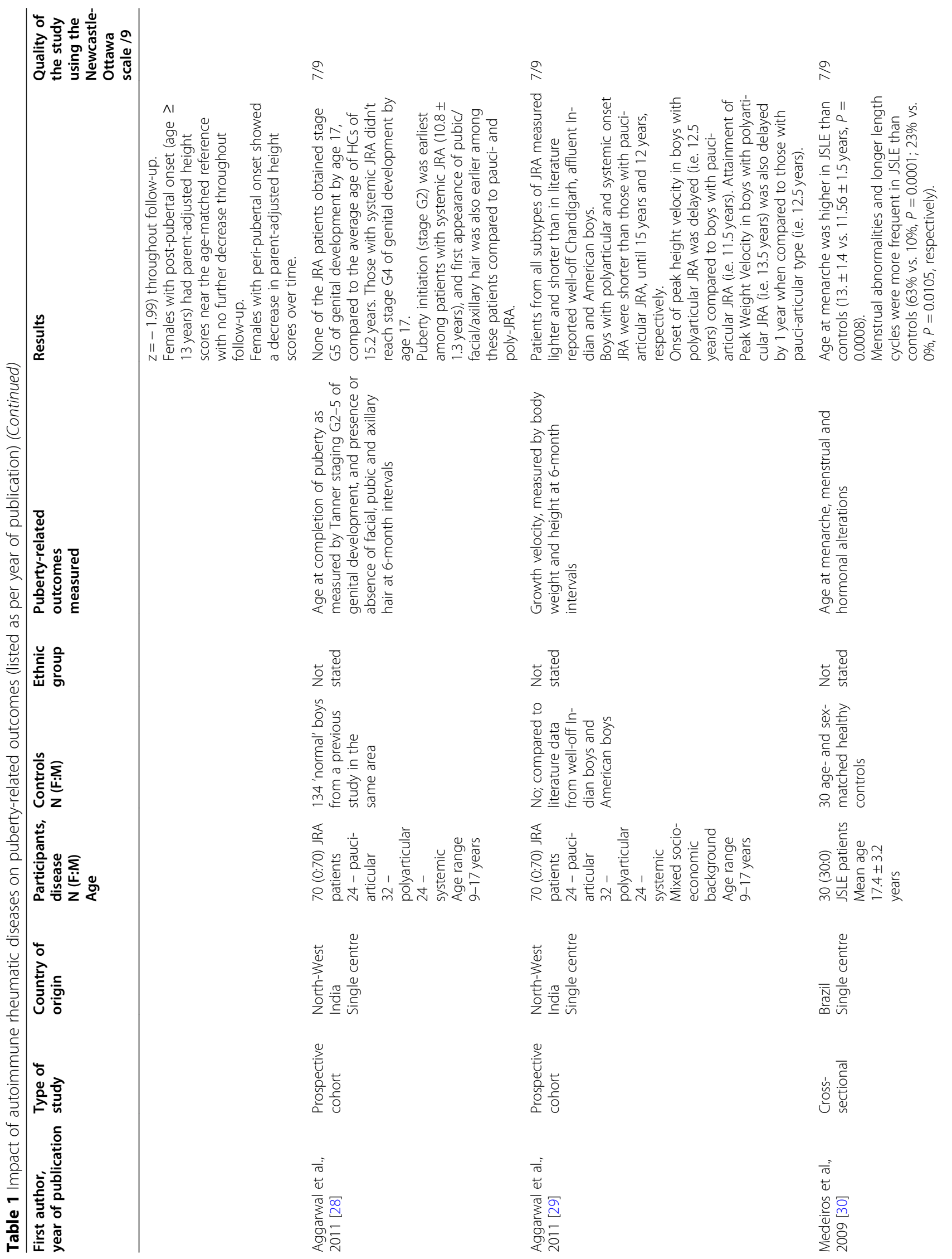




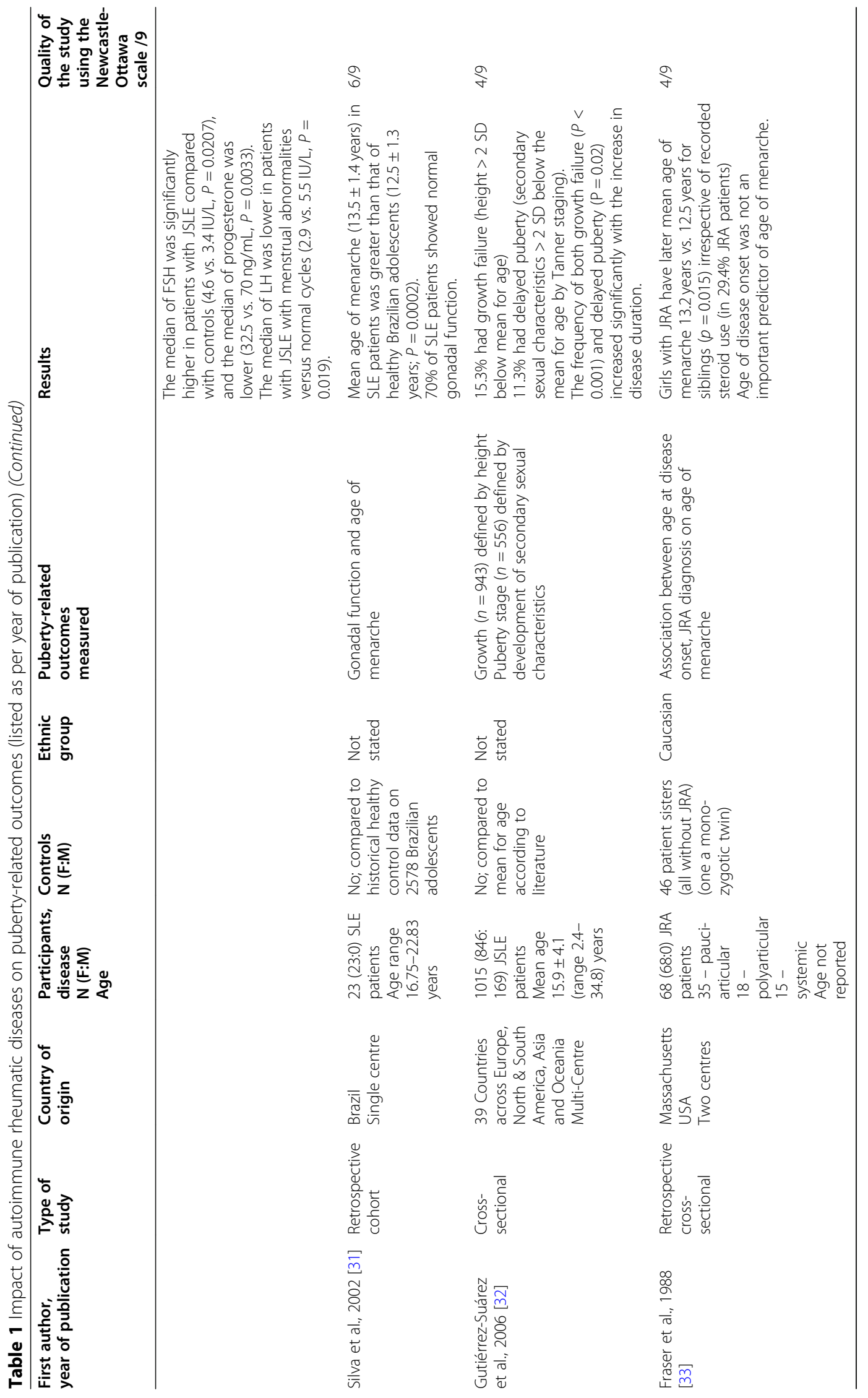




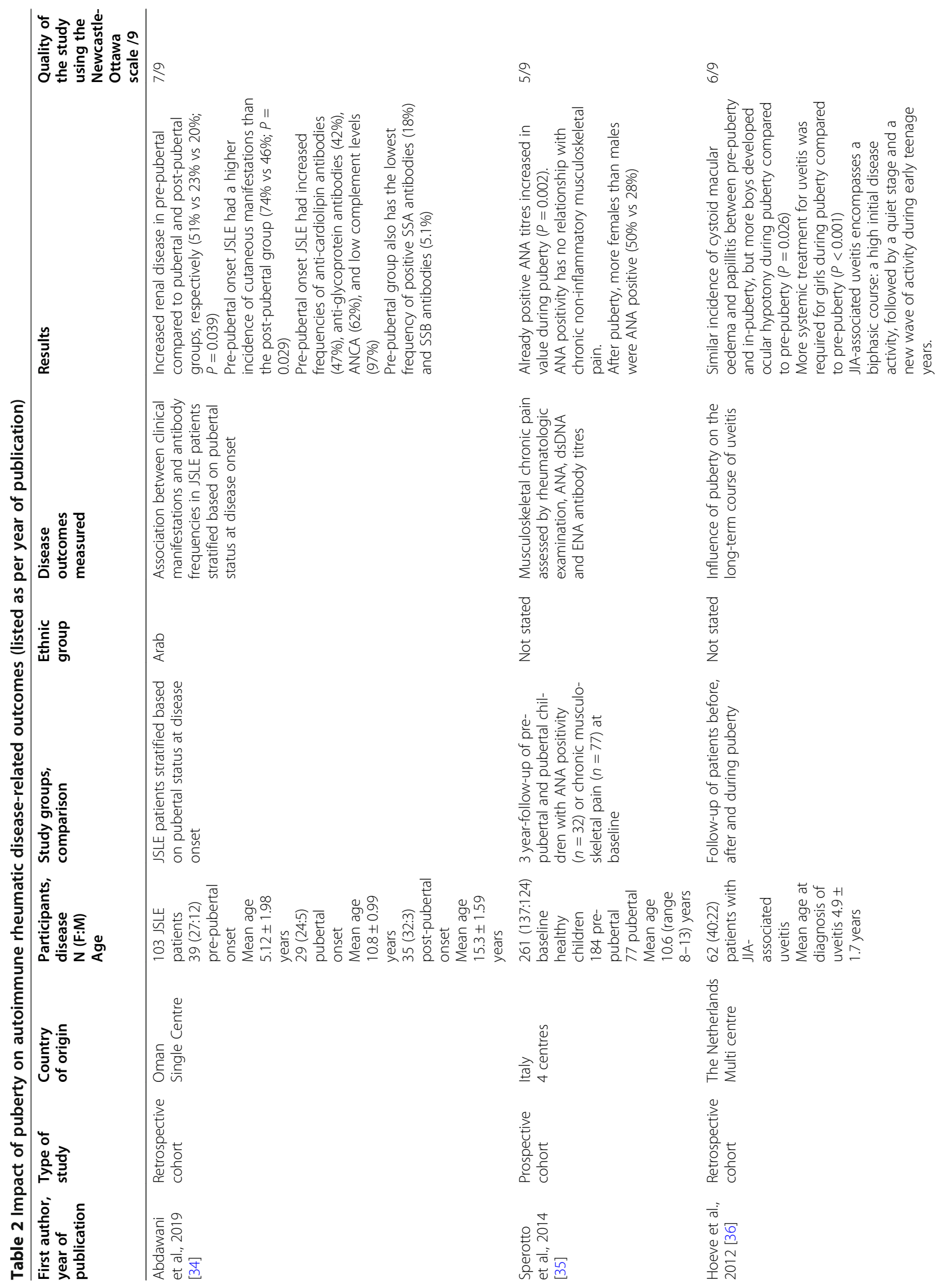




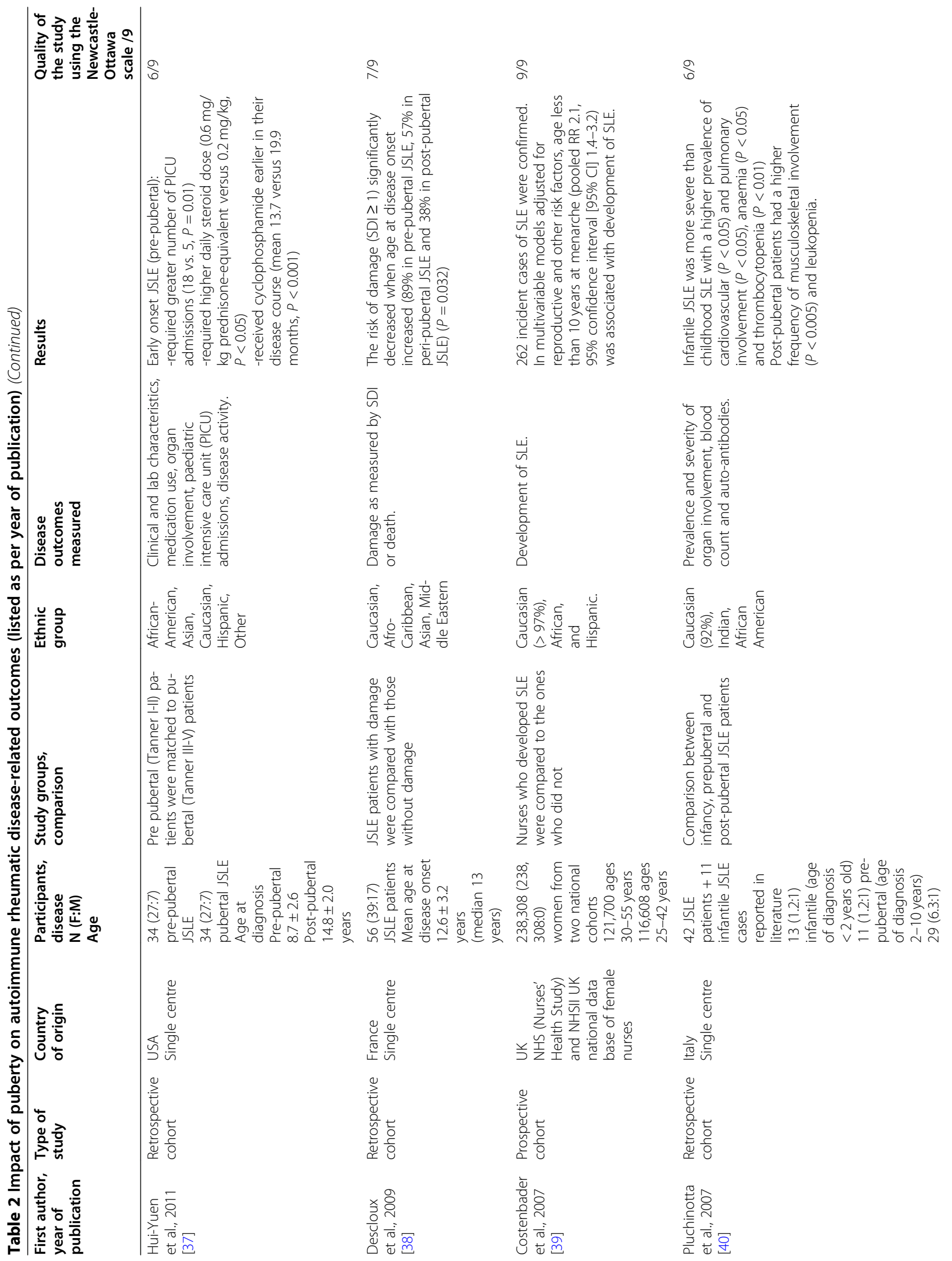




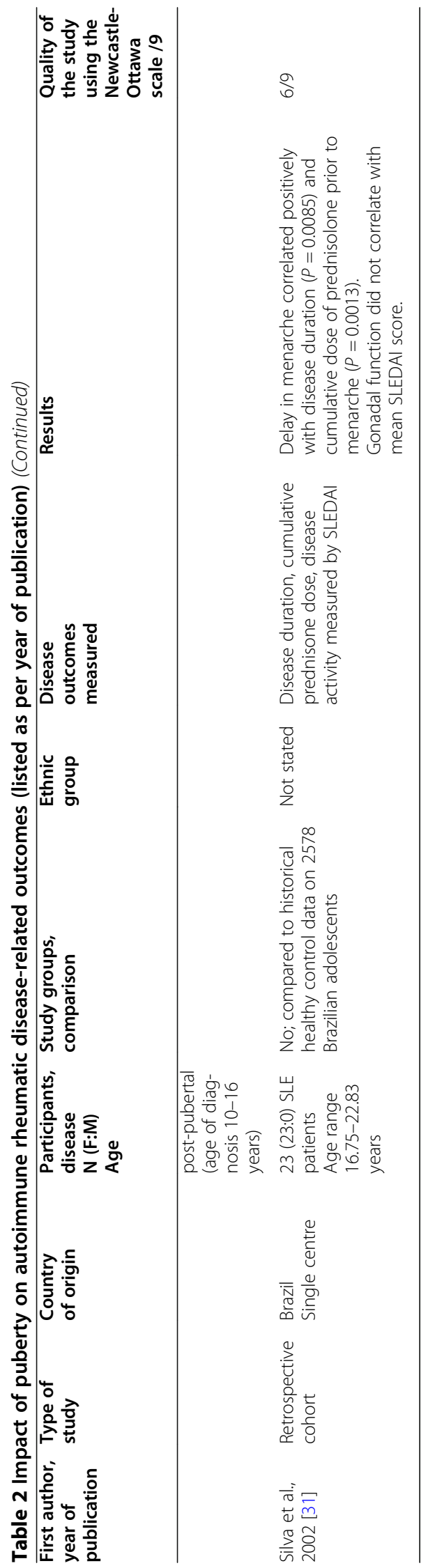


The Cohen's Kappa Statistic value calculated for the agreement reached by the manual screening of the paper abstracts was 0.69 (95\%CI 0.682-0.71), while the screening of the full-text papers reached an agreement of 0.81 (95\%CI 0.79-0.82).

The quality assessment of the included studies according to the Newcastle-Ottawa Scale, assessing criteria such as selection, comparability and outcome, ranged from 4 to $9 / 9$, showing a small to moderate risk of bias overall (Tables 1 and 2).

\section{Impact of autoimmune rheumatic diseases on puberty- related outcomes}

The disease outcome measures investigated in JIA/ JRA studies included cumulative dose of steroids, disease duration, disease activity, height, weight and age [26], as well as diagnosis [26-28, 33], type of JIA (systemic) [28] and age at disease onset [33]. Studies investigating the impact of JSLE on puberty were exclusively focused on evaluating the impact of being diagnosed with JSLE on puberty-related outcomes [13, 30, 31]. The following aspects of puberty were investigated: age at puberty onset; Tanner staging G2-5 of genital development [28]; presence or absence of facial, pubic and axillary hair [28]; age at menarche [30, 31, 33]; menstrual abnormalities and length of menstrual cycles, follicular stimulating hormone (FSH) and luteinizing hormone ( $\mathrm{LH}$ ) levels [30].

All the studies investigating the impact of JIA/JSLE on puberty reported some extent of delayed puberty in children with these conditions compared to healthy controls. Aggarwal et al. reported earlier puberty onset (Tanner stage G2 and onset of pubic/facial/axillary hair) in boys with systemic JIA compared to oligo- and polyarticular JIA [28], although despite this, the completion of puberty (defined as Tanner stage G5 achievement) was delayed in all male JIA patients compared to healthy controls. One study investigated the impact of JRA diagnosis on BMI and height, and found both to be significantly lower in JRA patients compared to age-matched healthy controls [27]. Although there is evidence of growth delay associated with JIA in both boys and girls, the JRA clinical phenotype had a differential impact on growth in peri-pubertal Indian boys: boys with polyarticular and systemic onset JRA were shorter than those with pauci-articular JRA, until 15 years and 12 years of age, respectively [29]. Similarly, adolescent JSLE patients experienced delayed puberty and growth retardation when compared to healthy controls as reported in the literature, and both correlated with the disease duration [32]. The impact of ARD-related treatment on puberty was sparsely evaluated: one study in JIA showed a significant association between both the dose and an earlier age at administration of corticosteroids with delayed puberty in boys [26], while an older study did not show any impact of steroid use in girls with JRA on age at menarche compared to healthy controls [33]. One study investigated additional puberty-related outcomes, and found that menstrual and hormonal abnormalities were significantly more common in patients with JSLE than in healthy controls [30].

\section{Impact of puberty on autoimmune rheumatic disease- related outcomes}

The studies investigating the impact of puberty on autoimmune rheumatic disease manifestations and severity included the following puberty parameters: Tanner stages [34, 36-38, 40], age at menarche [31, 39], female reproductive factors [39] and gonadal function [31]. One study focused on patients with JIA-associated uveitis [36], all the remaining studies investigated patients with JSLE or healthy controls who developed adult-onset SLE.

The impact of age at onset and puberty on JSLE severity was consistent across studies, showing similar trends of more severe disease in patients with earlier onset (pre-pubertal) compared to post-pubertal patients, irrespective of outcome measures used (renal, cardiovascular, pulmonary and haematological involvement; paediatric intensive care unit [PICU] admissions; steroid and cyclophosphamide use; autoantibodies and complement C3 levels, and accrued lupus-related damage). Of note, none of the JSLE studies investigating the impact of puberty evaluated overlapping outcome measures to allow for cross-validation of findings. One study showed, through multivariate analysis, that an age of less than 10 years at menarche was associated with the risk of SLE development later in life [39]. Another study [31] found that delayed onset of menarche related strongly with both JSLE disease duration and cumulative prednisolone dose pre-menarche. This may be because both chronic disease as well as chronic use of corticosteroids can suppress growth, which can delay menarche and slow down puberty progression.

We identified only one study investigating pubertyrelated outcomes in ARD patients stratified based on sex [36]. This study found increased incidence of ocular hypotony during puberty in boys with JIAassociated uveitis, and also found that pubertal females more frequently required systemic treatment for uveitis compared to either sex pre-puberty. The same study observed a biphasic course in JIAassociated uveitis in both boys and girls: a high activity at diagnosis, followed by a reduction, and a new wave of activity during early teenage years [36]. However, the second activity wave cannot be linked to pubertal changes directly, as the authors do not provide puberty measurements or stages. 


\section{Discussion}

Adolescence is associated with significant changes that are initiated and mediated by sex hormones. Recent efforts collecting detailed prospective data help to understand the impact of hormonal changes during the transition from childhood to adolescence on psychological and physical health [41]. During and after puberty, ARDs are more common in females than in males. Research suggests a potential role for sex hormones in triggering autoimmune processes, and in influencing the outcomes of ARDs.

With this systematic review we set out to describe the evidence supporting the bidirectional relationship between puberty and ARDs. It has highlighted the large heterogeneity of the available literature. Overall, the studies identified had moderate quality, and investigated, with few exceptions, cohorts of a relatively small sample size. The majority were retrospective studies and provided insufficient detail on the management of missing data. All studies focussed on JIA/JRA or (J)SLE. Because of the heterogeneity of disease-specific outcome measures reported, there was no scope to perform a metaanalysis. Despite the puberty-related outcomes being less heterogeneous - the majority of the studies reported the age at menarche or completion of various Tanner stages - a meta-analysis of the impact of one specific ARD on puberty could not be performed, due to the variation of result reporting and the small number of studies per disease. Despite being aware that puberty has significant impact on growth, and that the growth spurt is a useful clinical puberty surrogate outcome for boys [42], we identified only one paper assessing the growth velocity delay during puberty in boys with JIA [29]. However, there are many studies in JIA showing reduced attained height in JIA patients over age 18 [43], as well as reduced height 3 years after diagnosis (median age 10.4) in children with JIA compared to healthy controls [44]. Similarly, there is evidence of growth retardation at 2-year follow-up in patients with JSLE, which prompted the proposal of including growth failure and delayed puberty in the paediatric version of the Systemic Lupus International Collaborating Clinics/American College of Rheumatology Damage Index (SDI) [32]. It is unknown, however, whether growth retardation in young people with ARDs is a symptom of delayed puberty, or an effect of chronic illness in combination with growthinhibiting medications, such as corticosteroids [43].

Although a quantitative analysis was not possible, there were clinically relevant results worth mentioning. For example, a delay in puberty in patients with JIA/JSLE compared to controls was reported in all studies investigating the impact of these diseases on puberty outcomes. Lower height and weight than healthy controls, and menstrual and hormonal abnormalities, were also seen in ARD patients. Some evidence suggests the delay in puberty is positively correlated with (cumulative) corticosteroid dose, though further research is needed to confirm this; it is likely that the correlation reflects an indirect effect of disease severity, and delayed growth caused by corticosteroids [43, 45]. Clarifying this link is especially relevant considering that multiple articles reported more severe disease, and more need for (systemic) treatment, in children with pre-pubertal diagnosis of ARD, as compared to post-pubertal diagnosis.

Although our literature search did not identify papers assessing other ARDs with onset around the time of puberty, such as CRMO (age at onset 7-12) [46] or childhood granulomatosis with polyangiitis (median age at onset 11.7 years) [47], we recognise that the assessment of puberty-related outcomes is relevant for a larger group of rheumatic conditions than the ones captured in this review. In light of the limited quality of evidence in this systematic review, we want to propose a set of feasible clinical assessments of children and young people with autoimmune rheumatic diseases. These recommendations, based on the preceding results and the experience of our multidisciplinary clinical team, can be recorded at hospital visits to facilitate the understanding of disease and treatment impact on puberty-related outcomes. We suggest the following: 1) to establish start of puberty in all patients to ensure appropriate action can be taken if it is delayed (age $>13$ years in girls and $>14$ years in boys); 2) to record age at menarche in every patient to establish that it is not delayed (age > 16); 3) to record pubertal progress - by history/self-assessment and growth chart, and by clinical examination in case of concerns - at every clinical encounter until the completion of puberty, in accordance with the Childhood and Puberty Close monitoring Charts [48]; 4) to discuss menstrual abnormalities; 5) to have patient-centred discussions around starting treatments that are likely to (indirectly) impact puberty, such as steroids or cyclophosphamide, and ensure pubertal development is monitored in patients started on such treatments; 6) to propose endocrinology-rheumatology interdisciplinary assessments in selected cases of delayed puberty; 7) to raise patient/family awareness of features of delayed puberty; 8) to quantify puberty-related outcomes in damage scores annually, e.g. growth retardation, delayed puberty, or infertility (see Fig. 2). Quantifying outcomes will greatly improve care: it allows for close monitoring and provides a starting point for conversation - especially when including self-assessment - involving young people in their own care. 


\begin{tabular}{|c|c|c|c|}
\hline \multicolumn{4}{|c|}{$\begin{array}{l}\text { Clinical assessments of children and young people with autoimmune rheumatic diseases } \\
\text { Facilitating the understanding of ARDs and treatment impact on puberty-related outcomes }\end{array}$} \\
\hline $\begin{array}{l}\text { Discuss puberty issues } \\
\text { with patients and families } \\
\text { - Have a patient-centred } \\
\text { discussion when starting } \\
\text { treatment } \\
\text { - Raise awareness offeatures } \\
\text { of delayed puberty } \\
\text { - Discuss menstrual } \\
\text { abnormalities }\end{array}$ & $\begin{array}{l}\text { Routinely assess } \\
\text { development }\end{array}$ & $\begin{array}{l}\text { Have interdisciplinary } \\
\text { assessments } \\
\text { - Have an assessment with a } \\
\text { rheumatologist and an } \\
\text { endocrinologistwhen: } \\
\text { - Start of puberty is delayed } \\
\text { ○ }>13 y \text { years ơ }>14 \text { years } \\
\text { - Age at menarche }>16 \\
\text { years } \\
\text { - (Puberty) development } \\
\text { stagnates }\end{array}$ & $\begin{array}{l}\text { Create future possibilities } \\
\text { to improve outcomes } \\
\text { - Increase wellbeing of } \\
\text { patients and families } \\
\text { - Enable better clinical care } \\
\text { - Facilitate research }\end{array}$ \\
\hline
\end{tabular}

Fig. 2 Suggested clinical assessments of children and adolescents with autoimmune rheumatic diseases

These recommendations are both in line with the EULAR/PReS recommendations for the transitional care of young people with juvenile-onset rheumatic diseases [49], and with the general notion that routine developmental assessment is a core part of adolescent health care $[41,43]$. This supports our opinion that evidencebased knowledge is needed to improve outcomes.

Clinicians, patients and families will benefit from increased awareness of the relationship between puberty and ARDs. Not only will our recommended assessments inform individualised flare management during puberty; they will also facilitate future research into treatments that minimise the negative impact of ARD on pubertal development. Shedding light on the complex but important relationship between puberty and autoimmune rheumatic diseases allows young patients to have what all young people want: a chance to develop into the best version of themselves, without limitations.

\section{Authors' contributions}

$\mathrm{NdG}, \mathrm{MN}$ and CC wrote the manuscript. Articles were screened by MK and JG and evaluated by AR, HP and CC. Data was extracted by AR, HP and CC. ECR, ECJ and GEB contributed to the manuscript. The author(s) read and approved the final manuscript.

\section{Declarations}

\section{Competing interests}

The authors declare that they have no competing interests.

\section{Author details}

${ }^{1}$ Centre for Adolescent Rheumatology Versus Arthritis, Department of Medicine, University College London, Rayne Building, London W1CE 6JF, UK. ${ }^{2}$ Centre for Rheumatology Research, Division of Medicine, University College London, London, UK. ${ }^{3}$ University College London Medical School, London, UK. ${ }^{4}$ Department of Paediatric \& Adolescent Medicine and Endocrinology, University College London Hospital NHS Foundation Trust; University College London Great Ormond Street Institute of Child Health, London, UK.
Received: 20 July 2020 Accepted: 5 March 2021

Published online: 29 March 2021

\section{References}

1. Day FR, Elks CE, Murray A, Ong KK, Perry JRB. Puberty timing associated with diabetes, cardiovascular disease and also diverse health outcomes in men and women: The UK Biobank study. Sci Rep [Internet]. 201518 [cited 2020 Nov 12];5. Available from: https://pubmed.ncbi.nlm.nih.gov/26084728/

2. Markle JG, Fish EN. SeXX matters in immunity. Vol. 35, Trends in Immunology. 2014. p. 97-104.

3. Doran MF, Pond GR, Crowson CS, O'Fallon WM, Gabriel SE. Trends in incidence and mortality in rheumatoid arthritis in Rochester, Minnesota, over a forty-year period. Arthritis Rheum [Internet]. 2002 Mar 1 [cited 2020 Mar 18];46(3):625-31. Available from: http://doi.wiley.com/10.1002/art.509

4. Harbo HF, Gold R, Tintora M. Sex and gender issues in multiple sclerosis. Ther Adv Neurol Disord [Internet]. 2013 [cited 2020 Mar 18];6(4):237-48. Available from: http://tan.sagepub.com

5. Desai MK, Brinton RD. Autoimmune disease in women: Endocrine transition and risk across the lifespan. Vol. 10, Frontiers in Endocrinology. Frontiers Media S.A; 2019

6. Decaroli MC, Rochira V. Aging and sex hormones in males [Internet]. Vol. 8, Virulence. Taylor and Francis Inc.; 2017 [cited 2020 Nov 13]. p. 545-70. Available from: /pmc/articles/PMC5538340/?report=abstract.

7. Huang $J L$, Yao TC, See LC. Prevalence of pediatric systemic lupus erythematosus and juvenile chronic arthritis in a Chinese population: A nation-wide prospective population-based study in Taiwan. Clin Exp Rheumatol [Internet]. 2004;22(6):776-80 [cited 2020 Apr 21]Available from: http://www.ncbi.nlm.nih.gov/pubmed/15638056.

8. Evans AK, Licameli G, Brietzke S, Whittemore K, Kenna M. Pediatric facial nerve paralysis: patients, management and outcomes. Int J Pediatr Otorhinolaryngol. 2005;69(11):1521-8.

9. Murphy $\mathrm{G}$, Isenberg D. Effect of gender on clinical presentation in systemic lupus erythematosus. Rheumatology (Oxford) [Internet]. 2013 Dec [cited 2020 Apr 23];52(12):2108-15. Available from: http://www.ncbi.nlm.nih.gov/ pubmed/23641038.

10. Salpietro V, Polizzi A, Recca G, Ruggieri M. The role of puberty and adolescence in the pathobiology of pediatric multiple sclerosis. Mult Scler Demyelinating Disord [Internet]. 2018 Dec 22 [cited 2020 Apr 23];3(1):2. Available from: https://msddjournal.biomedcentral.com/articles/10.1186/s4 0893-017-0032-4

11. Pikwer M, Bergström U, Nilsson JÅ, Jacobsson L, Turesson C. Early menopause is an independent predictor of rheumatoid arthritis. Ann Rheum Dis [Internet]. 2012;71(3):378-81 [cited 2020 Mar 18]Available from: http://ard.bmj.com/content/71/3.toc.

12. Ahn JJ, O'Mahony J, Moshkova M, Hanwell HE, Singh $H$, Zhang MA, et al. Puberty in females enhances the risk of an outcome of multiple sclerosis in 
children and the development of central nervous system autoimmunity in mice. Mult Scler [Internet]. 2015 [cited 2020 Mar 18];21(6):735-48. Available from: http://msj.sagepub.com

13. Rygg M, Pistorio A, Ravelli A, Maghnie M, Di lorgi N, Bader-Meunier B, et al. A longitudinal PRINTO study on growth and puberty in juvenile systemic lupus erythematosus. Ann Rheum Dis [Internet]. 2012;71(4):511-7 [cited 2020 Mar 18]Available from: http://ard.bmj.com/.

14. Ceovic R, Mance M, Mokos ZB, Svetec M, Kostovic K, Stulhofer Buzina D. Psoriasis: Female Skin Changes in Various Hormonal Stages throughout LifePuberty, Pregnancy, and Menopause. Biomed Res Int [Internet]. 2013 [cited 2020 Mar 18];2013. Available from: http://dx.

15. Wilhelmson AS, Lantero Rodriguez $M$, Stubelius A, Fogelstrand $P$, Johansson I, Buechler MB, et al. Testosterone is an endogenous regulator of BAFF and splenic B cell number. Nat Commun [Internet]. 2018 [cited 2020 Mar 18]; 9(1). Available from: www.nature.com/naturecommunications

16. Harbuz MS, Perveen-Gill Z, Lightman SL, Jessop DS. A protective role for testosterone in adjuvant-induced arthritis. Br J Rheumatol [Internet]. 1995 Dec [cited 2020 Apr 23];34(12):1117-22. Available from: http://www.ncbi. nlm.nih.gov/pubmed/8608351.

17. Keith RC, Sokolove J, Edelman BL, Lahey L, Redente EF, Holers VM, et al. Testosterone is protective in the sexually dimorphic development of arthritis and lung disease in SKG mice. Arthritis Rheum. 2013 Jun;65(6):1487-93.

18. Gordon C, Wallace DJ, Shinada S, Kalunian KC, Forbess L, Braunstein GD, et al. Testosterone patches in the management of patients with mild/ moderate systemic lupus erythematosus. Rheumatology [Internet]. 2008 [cited 2020 Mar 18];47(3):334-8. Available from: https://academic.oup.com/ rheumatology/article-abstract/47/3/334/1776687

19. Hall GM, Larbre JP, Spector TD, Perry LA, Da Silva JA. A randomized trial of testosterone therapy in males with rheumatoid arthritis. Br J Rheumatol [Internet]. 1996 Jun [cited 2020 Apr 23];35(6):568-73. Available from: http:// www.ncbi.nlm.nih.gov/pubmed/8670579.

20. Voskuhl RR, Wang H, Wu TCJ, Sicotte NL, Nakamura K, Kurth F, et al. Estriol combined with glatiramer acetate for women with relapsing-remitting multiple sclerosis: a randomised, placebo-controlled, phase 2 trial. Lancet Neurol [Internet]. 2016 Jan 1 [cited 2020 Apr 23];15(1):35-46. Available from: http://www.ncbi.nlm.nih.gov/pubmed/26621682

21. Schoenau E, Neu CM, Mokov E, Wassmer G, Manz F. Influence of Puberty on Muscle Area and Cortical Bone Area of the Forearm in Boys and Girls. J Clin Endocrinol Metab [Internet]. 2000 Mar 1 [cited 2020 Jun 15];85(3):1095-8. Available from: https://academic.oup.com/jcem/article-lookup/doi/10.1210/ jcem.85.3.6451

22. Sperotto F, Brachi S, Vittadello F, Zulian F. Musculoskeletal pain in schoolchildren across puberty: A 3-year follow-up study. Pediatr Rheumatol. 2015;15:13(1).

23. Cossio Bolaños MA, Andruske $\mathrm{CL}$, de Arruda M, Sulla-Torres J, Urra-Albornoz C, Rivera-Portugal M, et al. Muscle Mass in Children and Adolescents: Proposed Equations and Reference Values for Assessment. Front Endocrinol (Lausanne) [Internet]. 2019 Aug 28 [cited 2020 Jun 15];10(AUG):583. Available from: https://www.frontiersin.org/article/10.3389/fendo.2019. 00583/full

24. Tobiume H, Kanzaki S, Hida S, Ono T, Moriwake T, Yamauchi S, et al. Serum bone alkaline phosphatase Isoenzyme levels in Normal children and children with growth hormone $(\mathrm{GH})$ deficiency: A potential marker for bone formation and response to GH therapy 1. J Clin Endocrinol Metab. 1997 Jul; 82(7):2056-61.

25. Deeks JJ, Dinnes J, D'Amico R, Sowden AJ, Sakarovitch C, Song F, et al. Evaluating non-randomised intervention studies. Vol. 7, Health Technology Assessment. NIHR Journals Library; 2003.

26. El Badri D, Rostom S, Bouaddi I, Hassani A, Chkirate B, Amine B, et al. Sexual maturation in Moroccan patients with juvenile idiopathic arthritis. Rheumatol Int. 2014;34(5):665-8.

27. Maher SE, Ali FI. Sexual maturation in Egyptian boys and girls with juvenile rheumatoid arthritis. Rheumatol Int. 2013;33(8):2123-6.

28. Aggarwal B, Bhalla AK, Singh S. Sexual maturation in boys with juvenile rheumatoid arthritis. Rheumatol Int. 2011;31(11):1419-21.

29. Aggarwal B, Bhalla AK, Singh S. Longitudinal growth attainments of Indian boys with Juvenile Rheumatoid Arthritis. Rheumatol Int [Internet]. 2011 May [cited 2020 Nov 18];31(5):635-40. Available from: https://pubmed.ncbi.nlm. nih.gov/20054693/

30. Medeiros PB, Febrônio M V , Bonfá E, Borba EF, Takiuti AD, Silva CAA Menstrual and hormonal alterations in juvenile systemic lupus erythematosus. Lupus [Internet]. 2009 [cited 2020 Mar 18];18(1):38-43. Available from: http://lup.sagepub.com

31. Silva CAA, Leal MM, Leone C, Simone VP, Takiuti AD, Saito MI, et al. Gonadal function in adolescents and young women with juvenile systemic lupus erythematosus. Lupus [Internet]. 2002 [cited 2020 Mar 18];11(7):419-25. Available from: www.lupus-journal.com

32. Gutiérrez-Suárez R, Ruperto N, Gastaldi R, Pistorio A, Felici E, Burgos-Vargas $R$, et al. A proposal for a pediatric version of the Systemic Lupus International Collaborating Clinics/American College of Rheumatology Damage Index based on the analysis of 1,015 patients with juvenile-onset systemic lupus erythematosus. Arthritis Rheum [Internet]. 2006 Sep [cited 2020 Nov 18];54(9):2989-96. Available from: https://pubmed.ncbi.nlm.nih. gov/16947634/

33. Fraser PA, Hoch S, Erlandson D, Partridge R, Jackson JM. The timing of menarche in juvenile rheumatoid arthritis. J Adolesc Health Care [Internet]. 1988 Nov [cited 2020 Apr 23];9(6):483-7. Available from: http://www.ncbi. nlm.nih.gov/pubmed/3182363.

34. Abdwani R, Abdalla E, Al-Zakwani I. Unique Characteristics of Prepubertal Onset Systemic Lupus Erythematosus. Int J Pediatr [Internet]. 2019 [cited 2020 mar 18];2019:1-7. Available from: https://doi.org/10.1155/2019/953 7065 .

35. Sperotto F, Cuffaro G, Brachi S, Seguso M, Zulian F. Prevalence of Antinuclear Antibodies in Schoolchildren During Puberty and Possible Relationship with Musculoskeletal Pain: A Longitudinal Study. J Rheumatol Rheumatol J March [Internet]. 2014 [cited 2020 Mar 18];41(7):2020. Available from: http://www.jrheum.org/content/41/7/1405 http://www.jrheum.org/a lerts1.SignupforTOCsandotheralerts http://jrheum.com/faqwww.jrheum.org www.jrheum.orgDownloadedfrom

36. Hoeve M, Ayuso VK, Schalij-Delfos NE, Los LI, Rothova A, De Boer JH. The clinical course of juvenile idiopathic arthritis-associated uveitis in childhood and puberty. Br J Ophthalmol [Internet]. 2012;96(6):852-6 [cited 2020 Mar 18]Available from: http://bjo.bmj.com/.

37. Hui-Yuen JS, Imundo LF, Avitabile C, Kahn PJ, Eichenfield AH, Levy DM. Early versus later onset childhood-onset systemic lupus erythematosus: Clinical features, treatment and outcome. Lupus [Internet]. 2011 [cited 2020 Mar 18];20:952-9. Available from: http://lup.sagepub.com

38. Descloux E, Durieu I, Cochat P, Vital-Durand D, Ninet J, Fabien N, et al. Influence of age at disease onset in the outcome of paediatric systemic lupus erythematosus. Rheumatology [Internet]. 2009 [cited 2020 Mar 18]; 48(7):779-84. Available from: https://academic.oup.com/rheumatology/a rticle-abstract/48/7/779/1788980

39. Costenbader KH, Feskanich D, Stampfer MJ, Karlson EW. Reproductive and menopausal factors and risk of systemic lupus erythematosus in women. Arthritis Rheum [Internet]. 2007 Apr 1 [cited 2020 Mar 18];56(4):1251-62. Available from: http://doi.wiley.com/10.1002/art.22510

40. Pluchinotta FR, Schiavo B, Vittadello F, Martini G, Perilongo G, Zulian F, et al. Distinctive clinical features of pediatric systemic lupus erythematosus in three different age classes. Lupus [Internet]. 2007 [cited 2020 Mar 18];16: 550-5. Available from: http://lup.sagepub.com

41. Mundy LK, Simmons JG, Allen NB, Viner RM, Bayer JK, Olds T, et al. Study protocol: The Childhood to Adolescence Transition Study (CATS). BMC Pediatr [Internet]. 2013 Oct 8 [cited 2020 Nov 15];13(1). Available from: https://pubmed.ncbi.nlm.nih.gov/24103080/

42. Albertsson-Wikland KG, Niklasson A, Holmgren A, Gelander L, Nierop AFM. A new type of pubertal height reference based on growth aligned for onset of pubertal growth. J Pediatr Endocrinol Metab [Internet]. 2020 Sep 1 [cited 2020 Nov 18];33(9):1173-82. Available from: https://pubmed.ncbi.nlm.nih. gov/32809956/

43. Wong SC, Dobie R, Altowati MA, Werther GA, Farquharson C, Ahmed SF. Growth and the growth hormone-insulin like growth factor 1 axis in children with chronic inflammation: Current Evidence, Gaps in Knowledge, and Future Directions [Internet]. Vol. 37, Endocrine Reviews. 2016. p. 62-110. Available from: https://academic.oup.com/edrv/article/37/1/62/2354716

44. McErlane F, Carrasco R, Kearsley-Fleet L, Baildam EM, Wedderburn LR, Foster $H E$, et al. Growth patterns in early juvenile idiopathic arthritis: Results from the Childhood Arthritis Prospective Study (CAPS). Semin Arthritis Rheum [Internet]. 2018 Aug 1 [cited 2020 Nov 18];48(1):53-60. Available from: https://pubmed.ncbi.nlm.nih.gov/29217290/

45. Umławska W, Prusek-Dudkiewicz A. Growth retardation and delayed puberty in children and adolescents with juvenile idiopathic arthritis. Vol. 6, Archives of Medical Science: Termedia Publishing; 2010. p. 19-23. 
46. Hofmann SR, Kapplusch F, Girschick HJ, Morbach H, Pablik J, Ferguson PJ, et al. Chronic Recurrent Multifocal Osteomyelitis (CRMO): Presentation, Pathogenesis, and Treatment [Internet]. Vol. 15, Current Osteoporosis Reports. Current Medicine Group LLC 1; 2017 [cited 2020 Nov 15]. p. 542-54. Available from: /pmc/articles/PMC5705736/ ?report=abstract.

47. Bohm M, Gonzalez Fernandez Ml, Ozen S, Pistorio A, Dolezalova P, Brogan P, et al. Clinical features of childhood granulomatosis with polyangiitis (wegener's granulomatosis). Pediatr Rheumatol [Internet]. 2014 May 26 [cited 2020 Nov 18];12(1). Available from: https://pubmed.ncbi.nlm.nih. gov/24891844/

48. Royal College of Paediatrics and Child Health. UK-WHO growth charts - childhood and puberty close monitoring (CPCM) chart [Internet]. 2013 [cited 2020 Apr 24]. Available from: https://www.rcpch.ac.uk/ resources/uk-who-growth-charts-childhood-puberty-close-monitoringcpcm-chart

49. Foster HE, Minden $\mathrm{K}$, Clemente $\mathrm{D}$, Leon L, Mcdonagh JE, Kamphuis S, et al. EULAR/PReS standards and recommendations for the transitional care of young people with juvenile-onset rheumatic diseases. [cited 2020 Jun 10]; Available from: http://ard.bmj.com/

\section{Publisher's Note}

Springer Nature remains neutral with regard to jurisdictional claims in published maps and institutional affiliations.

Ready to submit your research? Choose BMC and benefit from:

- fast, convenient online submission

- thorough peer review by experienced researchers in your field

- rapid publication on acceptance

- support for research data, including large and complex data types

- gold Open Access which fosters wider collaboration and increased citations

- maximum visibility for your research: over $100 \mathrm{M}$ website views per year

At $\mathrm{BMC}$, research is always in progress.

Learn more biomedcentral.com/submissions 